\title{
COMMENT
}

\section{Global Child Health: beyond surviving to thriving}

\author{
Tina L. Cheng (D) ${ }^{1}$ and Nicole Shilkofski ${ }^{1}$ for the Pediatric Policy Council \\ Pediatric Research (2019) 86:683-684; https://doi.org/10.1038/s41390-019-0574-6
}

Improved child survival worldwide has been a tremendous success story. In 2000, the Millennium Summit of the United Nations established reducing child mortality as one of eight Millennium Development Goals for the year 2015. ${ }^{1}$ In 1990, one in 11 children died before reaching age 5; by 2017, it had fallen to one in $26^{2}$ Between 1990 and 2017 under-five mortality rates declined from 93.2 per 1000 live births to 39.1 per 1000 live births, with the rate falling in all World Health Organization regions. ${ }^{3}$ Mortality rates among older children and young adolescents (aged 5-14) also dropped, by more than $50 \%{ }^{2}$ Yet, despite this survival success, too many children continue to live under adverse conditions that do not allow them to develop, learn, work, and thrive to healthy, productive adulthood. In addition, too many countries were unable to achieve the targeted Millennium Development Goals in child and maternal health.

Whether living in impoverished families or marginalized communities, children continue to die because of their status and the environments into which they are born. In 2015 the United Nations General Assembly adopted seventeen Sustainable Development Goals to be achieved by the year $2030 .{ }^{4}$ These goals address global challenges including poverty, inequality, climate change, environmental degradation, prosperity, and peace and justice. With the Sustainable Development Goals, the focus has expanded from child survival to addressing the psychosocial and physical environment that strongly influence the developmental and health outcomes needed for children to thrive.

A global focus on adverse childhood conditions and thriving is critical because the world is increasingly interconnected in health and disease. Also, a growing proportion of births worldwide occur in countries outside North America. It is estimated that by 2050 , the African continent will account for $42 \%$ of all global births and $40 \%$ of all children under the age of $18 .^{5}$ The article in this month's issue by Berens et al. ${ }^{6}$ contributes to this necessary focus by developing a measure of the psychosocial conditions that influence a child's ability to thrive in the austere conditions of a resource-limited setting. The study is an excellent example of collaborative research that attempts to decipher how adversity can disrupt foundational developmental processes, but also incorporates appropriate cultural humility in its international context and framework for local adaptation in Bangladesh. They are commended for their consideration of multiple dimensions of validity and community participatory processes including conducting interviews and focus groups with parents and pretesting questions using cognitive interviewing methods. These are important components in measure development for a specific population. Translation and back translation of measures to other languages also requires careful attention. Their validation of a Childhood Psychosocial Adversity Scale used in Bangladesh can help assess early childhood needs and guide interventions on a population level.

It is well known from the literature on adverse childhood experiences (ACEs) that chronic activation of the stress response can lead to poor health outcomes beyond early childhood. These include dysregulation of the neuroendocrine and immune system development, altered cardiovascular functioning, metabolic dysregulation leading to obesity and type 2 diabetes, and epigenetic modifications that alter gene expression. ${ }^{7-11}$ Differential risk susceptibility in individual children can be accounted for by adaptive capacities that are influenced by supportive environments; hence the need for emphasis on development of such support in settings worldwide. Amelioration of the toxic stress response and understanding how the response can be mitigated in global health settings should be a high priority for the worldwide pediatric community in order to promote resiliency and buffering of the stress response for all children. This requires an explicit focus on social determinants of health and the social and physical environments of children and their families. Evidence suggests that interventions to create strong social relationships may prevent and ward off long-term impacts of ACEs. Interventions and policies to prevent and buffer adversities such as those emphasized in the Sustainable Development Goals are critical to ensuring the health of the world's children.

In 2019, the World Health Organization identified ten Threats to Global Health. ${ }^{12}$ While six threats relate to infectious disease (global influenza pandemic, antimicrobial resistance, Ebola and other high threat pathogens, vaccine hesitancy, dengue, HIV), four relate to the psychosocial and physical environment or access to care (air pollution and climate change, fragile and vulnerable settings, non- communicable diseases, weak primary health care). For children worldwide the focus must remain on infectious disease while expanding to address social determinants of health which influence susceptibility to infection and other diseases.

The first Sustainable Development Goal is "No Poverty", a goal that would disproportionately improve the lives of children. The 2016 UNICEF report Ending Extreme Poverty: A Focus on Children ${ }^{13}$ found that children are more than twice as likely as adults to live in extreme poverty. In 2013, $19.5 \%$ of children in low and middleincome countries (LMICs) were living in households that survived on an average of US $\$ 1.90$ a day or less per person (compared with only $9.2 \%$ of adults). Globally almost 385 million children live in extreme poverty, with the youngest children most at risk. The World Bank's flagship report Poverty and Shared Prosperity 2016: Taking on Inequality ${ }^{14}$ documented that half of the 767 million people globally living on less than $\$ 1.90$ per day are under the age of 18. These estimates were based on data from 89 countries representing $83 \%$ of the developing world's population. It is clear that poverty is associated with negative health and

1Department of Pediatrics, Johns Hopkins University School of Medicine, Baltimore, MD, USA
Correspondence: Tina L. Cheng (Tcheng2@jhmi.edu)

Published online: 9 September 2019 
developmental outcomes; a robust literature associates income with key health indicators such as risk of chronic disease, health promotion behaviors, and life expectancy. ${ }^{15}$

The second Sustainable Development Goal of "zero hunger" by 2030 is under threat. Last month's United Nations report State of Feed Security and Nutrition in the World $2019^{16}$ warned that, after nearly a decade of progress, the number of people who suffer from hunger has increased over the past 3 years. They found that one of every nine people globally suffer from hunger today and that maternal and child undernutrition contributes to $45 \%$ of deaths in children under five. Childhood stunting is decreasing too slowly while overweight and obesity are on the rise in almost all countries. To safeguard food security and nutrition the report supports economic and social policies that help counteract the effects of economic slowdowns or downturns, including guaranteed funding of social safety nets and universal access to health and quality education. In addition, multisectoral policies must address food insecurity and malnutrition.

Berens et al. $^{6}$ posit that their adapted Childhood Psychosocial Adversity Scale (CPAS) may support work aiming to characterize pathways that link poverty to poorer outcomes for children. Their study tool attempted to capture poverty-related psychological burdens that caregivers may face, including financial concerns and food insecurity. While these issues are widespread globally, their epidemiologic burden is higher in LMICs where implications of the wealth gap are often largest. The 2017 report Communities in Action: Pathways to Health Equity ${ }^{15}$ identified the unequal allocation of power and resources (goods, services, and societal attention) as a root cause of health inequity. The report outlined how this can manifest in unequal social, economic and environmental conditions. While the report focuses on the United States, the inequality in these conditions is even more salient in LMIC settings such as Bangladesh where the Berens study takes place. This, again, is a call to action to focus efforts more globally on ameliorating adversity for the children most at risk. UNICEF and the World Bank Group have called on governments and the healthcare sector to strengthen child-sensitive social protection systems; prioritize investments in education, health, sanitation and infrastructure to benefit the poorest children; and shape policy decisions so that economic growth benefits the poorest children.

Children are the human capital for a productive and sustainable future. Child health is foundational. It is incumbent upon us to enable and promote action toward global health improvements so that children not only survive, but thrive.

\section{FUNDING}

N.S.: Has received grant funding to develop curricula about adverse childhood experiences from the Association of Pediatric Program Directors and also has grant funding for an unrelated project from the U.S. Department of Education FulbrightHays Group Projects Abroad.

\section{PEDIATRIC POLICY COUNCIL (PPC)}

Scott C. Denne, MD, Chair, Pediatric Policy Council; Shale L. Wong, MD, MSPH, Representative to the PPC from the Academic Pediatric Association; Jean L. Raphael, MD, MPH, Representative to the PPC from the Academic Pediatric Association; Jonathan Davis, MD, Representative to the PPC from the American Pediatric Society; DeWayne Pursley, MD, MPH, Representative to the PPC from the American Pediatric
Society; Tina Cheng, MD, MPH, Representative to the PPC from the Association of Medical School Pediatric Department Chairs; Michael Artman, MD, Representative to the PPC from the Association of Medical School Pediatric Department Chairs; Shetal Shah, MD, Representative to the PPC from the Society for Pediatric Research; Joyce Javier, MD, MPH, MS, Representative to the PPC from the Society for Pediatric Research.

\section{AUTHOR CONTRIBUTIONS}

T.L.C. conceptualized and wrote the manuscript, revised each draft, and approved the final manuscript. N.S. helped to conceptualize the manuscript, reviewed and revised each draft of the manuscript, and approved the final manuscript as submitted.

\section{ADDITIONAL INFORMATION}

Competing interests: The authors declare no competing interests.

Publisher's note Springer Nature remains neutral with regard to jurisdictional claims in published maps and institutional affiliations.

\section{REFERENCES}

1. United Nations. Millennium Development Goals. https://www.un.org/ millenniumgoals/bkgd.shtml (2019).

2. United Nations Children's Fund (UNICEF). Under five mortality. https://data.unicef. org/topic/child-survival/under-five-mortality/ (2019).

3. UNICEF. Levels \& Trends in Child Mortality Report 2018. https://www.un.org/en/ development/desa/population/publications/mortality/child-mortality-report2018.asp (2019).

4. United Nations. Sustainable Development Goals. https://sustainabledevelopment. un.org/?menu=1300 (2019).

5. UNICEF. Generation 2030 Africa 2.0: Prioritizing investments in children to reap the demographic dividend. https://www.unicef.org/publications/files/ Generation_2030_Africa_2.0.pdf (2019).

6. Berens, A. et al. Cumulative psychosocial risk and early child development: validation and use of the Childhood Psychosocial Adversity Scale in global health research. Pediatr. Res. 2019. https://doi.org/10.1038/s41390-019-0431-7 [Epub ahead of print].

7. Black, P. H. The inflammatory response is an integral part of the stress response: implications for atherosclerosis, insulin resistance, type II diabetes and metabolic syndrome X. Brain Behav. Immun. 17, 350-364 (2003).

8. Campbell, F. et al. Early childhood investments substantially boost adult health. Science 343, 1478-1485 (2014).

9. Dinan, T. G. \& Cryan, J. F. Regulation of the stress response by the gut microbiota: implications for psychoneuroendocrinology. Psychoneuroendocrinology 37, 1369-1378 (2012).

10. Taylor, S. E., Way, B. M. \& Seeman, T. E. Early adversity and adult health outcomes. Dev. Psychopathol. 23, 939-954 (2011).

11. Vaiserman, A. M. Epigenetic programming by early-life stress: evidence from human populations. Developmental Dyn. 244, 254-265 (2015).

12. World Health Organization. Ten Threats to Global Health in 2019. https://www. who.int/emergencies/ten-threats-to-global-health-in-2019 (2019).

13. UNICEF. Ending Extreme Poverty: A Focus on Children 2016. https://www.unicef. org/publications/index_92826.html (2019).

14. World Bank. Poverty and Shared Prosperity 2016: Taking on Inequality. https:// www.worldbank.org/en/publication/poverty-and-shared-prosperity-2016 (2019).

15. National Academies of Sciences, Engineering and Medicine. 2017. Communities in action: Pathways to health equity. (The National Academies Press, Washington, DC, 2017). https://www.nap.edu/catalog/24624/communities-inaction-pathways-to-health-equity.

16. Food and Agriculture Organization of the United Nations. The Fate of Food Security and Nutrition in theWorld 2019: Safeguarding against economic slowdowns and downturns. http://www.fao.org/3/ca5162en/ca5162en.pdf (2019). 